$\xi=-1$

\title{
Study of wire-electrical discharge machining parameters of titanium alloy by using taguchi method
}

\author{
AVS Ram Prasad ${ }^{1 *}$, Koona Ramji ${ }^{2}$, B Raghu Kumar ${ }^{3}$ \\ ${ }^{1}$ Associate Professor, Department of Mechanical Engineering, Koneru Lakshmaiah Education Foundation, Vaddeswaram, Guntur, An- \\ dhra Pradesh, India 522502 \\ ${ }^{2}$ Professor, Department of Mechanical Engineering Andhra University, Vishakhapatnam, Andhra Pradesh, India \\ ${ }^{3}$ Professor, Department of Mechanical Engineering PVP Siddhartha Institute of Technology, Kanuru, Andhra Pradesh, India 520007 \\ *Corresponding author E-mail: avsrp_me@kluniversity.in
}

\begin{abstract}
Machining of Titanium alloys is difficult due to their chemical and physical properties namely excellent strength, chemical reactivity and low thermal conductivity. Traditional machining of such materials leads to formation of continuous chips and tool bits are subjected to chatter which leads to formation of poor surface on machined surface. In this study, Wire-EDM one of the most popular unconventional machining process which was used to machine such difficult-to-cut materials. Effect of Wire-EDM process parameters namely peak current, pulse-on- time, pulse-off-time, servo voltage on MRR and SR was investigated by Taguchi method. $0.25 \mathrm{~mm}$ brass wire was used in this process as electrode material. A surface roughness tester (Surftest 301) was used to measure surface roughness value of the machined work surface. A multi-response optimization technique was then utilized to optimize Wire-EDM process parameters for achieving maximum MRR and minimum SR simultaneously.
\end{abstract}

Keywords: Titanium Alloy; Wire-EDM; Brass Wire; Taguchi Methodology; Multi-Response Optimization; Surface Roughness Tester.

\section{Introduction}

Titanium and its alloys are having excellent chemical and mechanical properties and hence they were found as component materials which are used in aerospace and non-aerospace applications [1] Having physical properties such as excellent strength and light weight in nature these materials are used in preparation of automobile structures and engine components of aerospace industries. Due to their low elasticity and chemical reactivity with the tool materials, it is not east to cut Titanium alloys. Hence, development of advanced machining process for Titanium alloys arises in order to achieve better surface finish and tool life [2]. Wire-EDM which is a unconventional machining process was introduced to produce different variety of components with intricate shapes [3]. It is the process in which temperature is generated because of the electric spark developed between the two electrical conductors [4]. In this process, pulse generator unit will generate series of electrical pulses which are applied between the two conductors of electricity. The material is removed from the work surface because of the small spark energy developed in the narrow gap. Electro-erosion of work-piece is occurred because of large number of such developed tiny discharges [5].

Wire-EDM is a newly developed machining process which consists of varies number of electrical and non-electrical machining parameters [6]. Because of varies process parameters and difficult mechanism, achieving optimum performance from the machine is always a challenging task [7]. Therefore, a systematic approach is badly required and a demand for research studies was established, to find out the optimum parameter setting.
A good number of researches have been carried out in this area to find better optimal parameters while machining Titanium and its alloys [8-10]. Different types of optimization techniques are used by different authors for optimization of machining parameters. M.S. Hewidy et al [11] have used RSM technique to optimize WEDM machining parameters for minimum wire wear ratio and surface roughness. They have conducted 31 experiments on Inconel 601 material on a Wire-EDM machine. Peak current, Duty factor, Wire tension and Water pressure were taken as machining parameters and found that peak current as the significant parameter. Neeraj Sharma et al. [12]

Have used optimization technique to optimize process parameters namely Pulse-on-time, pulse-off-time, SV, IP and WT for maximum MRR and minimum SR. They have conducted experiments according to Central composite design (CCD). Vinod Kumar et al [13]. Have conducted experiments on Nimonic-90 using wire as electrode material to evaluate Surface roughness and Dimensional shift.

In the present study, effect of machining parameters namely IP, $\mathrm{T}_{\mathrm{on}}, \mathrm{T}_{\mathrm{off}} \mathrm{and} \mathrm{SV}$ on performance characteristics was investigated. Taguchi method was used to identify significant parameters on output responses namely MRR and SR. A multi criteria decision analysis, which is a multi- response optimization technique, was used to optimize the machining parameters in this paper for achieving maximum material removal rate and minimum surface roughness.

\section{Plan of experimentation}

In the present work, work piece material selected was Ti-6Al-4V alloy. It was considered for optimizing process parameters with 
multiple performance characteristics namely material removal rate (MRR) and surface roughness (SR). Machining parameters considered were: IP, $\mathrm{T}_{\mathrm{on}}, \mathrm{T}_{\mathrm{off}}$ and $\mathrm{SV}$. Orthogonal array Taguchi $\mathrm{L} 9$, as shown in Table (1) has been used by the author [14]. Taguchi method, which is a robust design methodology, is used for the conduction of experiments.

Table 1: Experimental Results after Machining Process from A.V.S Ram Prasad. [14]

\begin{tabular}{lllllll}
\multicolumn{2}{l}{ Prasad. [14] } & & & & & \\
\hline S NO & IP & Ton & Toff & SV & MRR & SR \\
\hline 1 & 10 & 105 & 75 & 40 & 2.91 & 1.8 \\
2 & 10 & 115 & 85 & 50 & 3.37 & 1.98 \\
3 & 10 & 125 & 95 & 60 & 3.76 & 2.34 \\
4 & 15 & 105 & 85 & 60 & 4.5 & 2.48 \\
5 & 15 & 115 & 95 & 40 & 6.25 & 2.71 \\
6 & 15 & 125 & 75 & 50 & 7.15 & 2.9 \\
7 & 20 & 105 & 95 & 50 & 6.32 & 2.41 \\
8 & 20 & 115 & 75 & 60 & 7.42 & 3.1 \\
9 & 20 & 125 & 85 & 40 & 6.05 & 2.79 \\
\hline
\end{tabular}

\section{AHP TOPSIS and experimental results}

The procedure for the selection of good alternative from those available alternatives by TOPSIS method is given below:

Step 1. Table 1 shows experimental values which describes about input parameters. Output characteristics namely MRR $\mathrm{mm}^{3} / \min ()$ nd SR $\left.R_{a}() \mu \mathrm{m}\right)$ investigated were also shown. Hence these output values are taken as input values in to decision matrix and source for this data is obtained from the Wire-EDM machining process.

Step 2. The next step is to determine all the important data required for the attributes in the form of decision matrix as given in Table 2.

Table 2: Decision Matrix $\left(x_{i j}\right)$

\begin{tabular}{lll}
\hline S NO & MRR & SR \\
\hline 1 & 2.91 & 1.8 \\
2 & 3.37 & 1.98 \\
3 & 3.76 & 2.34 \\
4 & 4.5 & 2.48 \\
5 & 6.25 & 2.71 \\
6 & 7.15 & 2.9 \\
7 & 6.32 & 2.41 \\
8 & 7.42 & 3.1 \\
9 & 6.05 & 2.79 \\
\hline
\end{tabular}

Step 3. Formation of normalised decision matrix as shown in Table 3 , by using the following equation and considering the decision matrix values as shown in above Table.

$$
r_{i j}=\frac{x_{i j}}{\sqrt{\sum_{i=r_{i j}^{m}}^{m} x^{2}}} \mathrm{i}=1,2 \ldots \ldots 9 ; \mathrm{j}=1,2 .
$$

\section{Where}

$\mathrm{i}=$ number of experimental runs.

$\mathrm{j}=$ performance characteristics.

$x_{i j}$ normalised value of $\mathrm{i}$-th experimental run associated with $\mathrm{j}$-th performance characteristics.

Table 3: Normalised Decision Matrix $\left(r_{i j}\right)$

\begin{tabular}{lll}
\hline S NO & MRR & SR \\
\hline 1 & 0.107516 & 0.236878 \\
2 & 0.202851 & 0.260565 \\
3 & 0.226326 & 0.307941 \\
4 & 0.270869 & 0.326365 \\
5 & 0.376207 & 0.356632 \\
6 & 0.43038 & 0.381636 \\
7 & 0.38042 & 0.317153 \\
8 & 0.446632 & 0.407956 \\
9 & 0.364168 & 0.36716 \\
\hline
\end{tabular}

Step 4. Calculation of weighted normalized decision matrix as shown in Table 4 by using weights which are obtained by AHP method. Weights for different parameters $\left(w_{j}\right)$ or $\mathrm{MRR}=0.5$, $\mathrm{SR}=0.5$.

$$
r_{i j}=* \mathrm{i}=1,2 \ldots 9 ; \mathrm{j}=1,2 .
$$

Table 4: Weighted Normalized Decision Matrix

\begin{tabular}{lll}
\hline S.NO & MRR & SR \\
\hline 1 & 0.087581 & 0.118439 \\
2 & 0.101425 & 0.130283 \\
3 & 0.113163 & 0.15397 \\
4 & 0.135434 & 0.163182 \\
5 & 0.188103 & 0.178316 \\
6 & 0.21519 & 0.190818 \\
7 & 0.19021 & 0.158576 \\
8 & 0.223316 & 0.203978 \\
9 & 0.182084 & 0.18358 \\
\hline
\end{tabular}

Step 5. Calculation of ideal best $\left(V^{+}\right)$nd ideal worst solutions $\left(V^{-}\right)$f jth output parameter have the optimal performance:

$$
\begin{aligned}
& V^{+}=\left\{\left[\max \left(S_{i j} \mid \mathrm{j} \in \mathrm{J}\right] \text { or }\left[\min S_{i j}\right) \square j \grave{\partial} J^{\prime}\right] i=1,2, \ldots \ldots \ldots 9\right.
\end{aligned}
$$

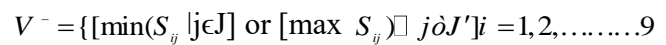

Where $V^{+}$epresents an ideal best solution $(0.223316,0.118439)$. Similarly, $V^{-}$epresents ideal worst solution $(0.087581,0.203978)$. Step 6. Determine computed distance measures.

The performance of these output values is measured as the important alternative distance $s_{i j}^{+}$rom the $V^{+}$alues and the bad alternative distance $s_{i j}^{-}$rom the $V^{-}$alues.

The following equations given below shows the performance of each alternative under the best and worst conditions

$s_{i}^{+}=\sqrt{\sum_{j=1}^{2}\left(D_{i j}-s_{i}^{+}\right)^{2}}$

$s_{i}^{-}=\sqrt{\sum_{j=1}^{2}\left(D_{i j}-s_{i}^{-}\right)^{2}}$

Where $\mathrm{j}=1,2$.

Step 7. Calculation of closeness coefficient and rank for alternatives.

Closeness coefficient $C_{i}=\frac{s_{i}^{-}}{s_{i}^{-}+s_{i}^{+}}$

Table 5: Closeness Coefficient Values

\begin{tabular}{lllll}
\hline SNO & $s_{i}^{+} \cdot$ & & & RANK \\
\hline 1 & 0.135735 & 0.085539 & 0.386575 & 7 \\
2 & 0.1224650 & 0.074984 & 0.379765 & 8 \\
3 & 0.115742 & 0.056171 & 0.326741 & 9 \\
4 & 0.098616 & 0.062883 & 0.389369 & 6 \\
5 & 0.069464 & 0.103746 & 0.598969 & 4 \\
6 & 0.072834 & 0.128286 & 0.637858 & 2 \\
7 & 0.052029 & 0.112223 & 0.683236 & 1 \\
8 & 0.085539 & 0.135735 & 0.613425 & 3 \\
9 & 0.077094 & 0.096679 & 0.556353 & 5 \\
\hline
\end{tabular}

The closeness coefficient values as shown in Table 5 have been computed by using equation (7). Therefore, a higher value of the relative closeness coefficient value means that the corresponding machining parameters are closer to the optimal levels. In other words, the optimization of machining parameters associated with the complex multiple performance characteristics can be converted into optimal resolution of single relative closeness value. Table 5 presents the results of worst and best alternative distances, relative coefficient values and their ranks. The results show that experiment value 7 has the highest relative closeness coefficient 
value. The optimum parameter setting obtained by using AHPTOPSIS method for Wire-EDM was 20 Peak current, 105 Pulse on time, 95 Pulse off time and 50 Servo voltages.

\section{Conclusion}

AHP-TOPSIS is employed to carryout multi-objective optimization in Wire-EDM of Ti-6Al-4V workpiece. All the four process parameters namely Peak current, Pulse on time, Pulse off time and Servo voltage of workpiece material have been studied simultaneously to optimize all important machining criteria keeping other process parameters constant. By using AHP-TOPSIS method Closeness Coefficient Values were found for the maximum MRR and minimum Surface Roughness. The optimum parameter setting obtained by using AHP-TOPSIS method for Wire-EDM was 20 Peak current, 105 Pulse on time, 95 Pulse off time and 50 Servo voltage.

\section{References}

[1] X. Yang, X., Liu, R.-C., 1999. Machining titanium and its alloys. Machining Science and Technology 3 (1), 107-139 https://doi.org/10.1080/10940349908945686.

[2] H.E., Boyer, T.L., Gall, 1985. Metals Handbook, American Society for Metals, Metal Park, Ohio, pp. 9.1-9.2.

[3] J.A., Mc Geough, 1988. Advanced Methods of Machining, Chapman \& Hall, London.

[4] E Bud Guitrau, (1988), "The EDM Handbook", Hanser Gardner Publications, Cincinnati, $\mathrm{OH}$

[5] S. Sarkar, S. Mitra, B. Bhattacharyya, (2005), Parametric analysis and optimization of wire electrical discharge machining of titanium aluminide alloy, Journal of Materials Processing Technology 159: 286-294. https://doi.org/10.1016/j.jmatprotec.2004.10.009.

[6] J.T Huang, Y.S Liao, H.C, Su, W.J, (1997), A Study on the machining parameters optimization of wire electrical discharge machining. Journal of Materials Processing Technology 71:487-493. https://doi.org/10.1016/S0924-0136(97)00117-9.

[7] T. A. El-Taweel, M.F. El-Safty, M.S Hewidy (2005), Moulding of machining parameters of wire electrical discharge machining of inconel 601 using RSM. J. Mater. Process. Technol. 169, 328. https://doi.org/10.1016/j.jmatprotec.2005.04.078.

[8] Alias, Aniza., Abdullah, Bulan., 2012. WEDM: Influence of Machine Feed Rate in Machining Titanium Ti-6Al-4V using Brass Wire and Constant Current (4A). Engineering Procedia, Elseiver 41, 1812-1817. https://doi.org/10.1016/j.proeng.2012.07.388.

[9] Alias, Aniza., Abdullah, Bulan., Mohd Abbas, Noorlina., 2012. Influence of Machine Feed Rate in WEDM of Titanium Ti-6Al-4V with Constant Current (6A) using Brass Wire. Engineering Procedia, Elseiver 41, 1806-1811.

[10] D. Satish Kumar, M. Kanthababu, V. Vajjiravelu, R. Anburaj, N. Tirumalai Sundarrajan.H. Arul (2011), Investigation of wire electrical discharge machining characteristics of AL6063/SiCp compisites. Int $\mathrm{J}$ Adv Manuf Technol. 56:975-986. https://doi.org/10.1007/s00170-011-3242-5.

[11] M.S. Hewidy, T.A. El-Taweel*, M.F. El-Safty. Modelling the machining parameters of wire electrical discharge machining of Inconel 601 using RSM. Journal of Materials Processing Technology 169 (2005) 328-336. https://doi.org/10.1016/j.jmatprotec.2005.04.078.

[12] Neeraj Sharma, Rajesh Khanna, Rahuldev Gupta. Multi Quality Characteristics of WEDM Process Parameters with RSM. Procedia $\begin{array}{llll}\text { Engineering } & 64 & \text { (2013) }\end{array}$ https://doi.org/10.1016/i.proeng.2013.09.146.

[13] Vinod Kumar, Vikas Kumar and Kamal Kumar Jangra. An experimental investigation and statistical modelling for trim cutting operation in WEDM of Nimonic-90. International Journal of Industrial Engineering Computations 62015.

[14] A.V.S Ram Prasad, Koona.Ramji, G.L.Datta. An Experimental Study of Wire EDM on Ti-6Al-4V Alloy. Procedia Materials Science 5, 2014, Page no.2567-2576.

[15] Dr. Seetaiah Kilaru, Hari Kishore K, Sravani T, Anvesh Chowdary L, Balaji T "Review and Analysis of Promising Technologies with Respect to fifth Generation Networks", 2014 First International Conference on Networks \& Soft Computing, ISSN:978-1-4799. 3486-7/14,pp.270-273, August2014.
[16] S. V. Manikanthan and T.Padmapriya "Recent Trends In M2m Communications in $4 \mathrm{~g}$ Networks and Evolution Towards 5g", International Journal of Pure and Applied Mathematics, ISSN NO 1314-3395, Vol-115, Issue -8, Sep 2017.

[17] T.Padmapriya, Ms. N. Dhivya, Ms U. Udhayamathi, "Minimizing Communication Cost In Wireless Sensor Networks To Avoid Packet Retransmission", International Innovative Research Journal of Engineering and Technology, Vol. 2, Special Issue, pp. 38-42.

[18] Dr. Seetaiah Kilaru, Hari Kishore K, Sravani T, Anvesh Chowdary L, Balaji T "Review and Analysis of Promising Technologies with Respect to fifth Generation Networks", 2014 First International Conference on Networks \& Soft Computing,ISSN:978-1-47993486-7/14,pp.270273,August 2014 